\title{
Reorganização prosódica na disartria
}

\section{Erica Reviglio Iliovitz UNICAMP}

\section{Abstract}

According to Felizatti (1998), dysarthria is a disorder in motor production that affects patterns of movement, coordination and strenght of articulatory organs. It can be caused by brain damage and it is usually characterized by slow speech. The analysis of some prosodic aspects of almost unintelligible dysarthric patients' speech indicates that the strange reaction their speech causes in their listeners is mainly due to the prosodic strategies they use (consciouslly or not) to improve their oral language intelligibility. In other words, despite the fact that dysarthric patients's brain lesions cause articulatory difficulties, they are able to compensate them through prosody. 


\section{INTRODUÇÃO}

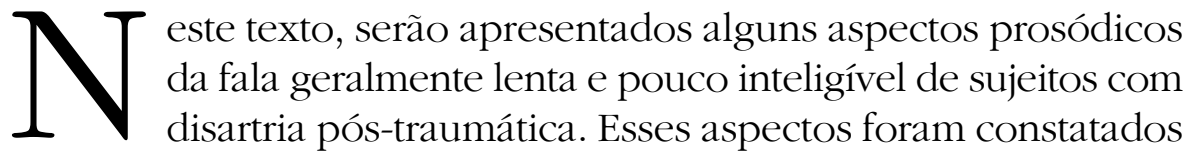
através de um estudo longitudinal (i.e., realizado no decorrer de um determinado período de tempo).

Um dos objetivos dos trabalhos longitudinais em geral é o de analisar e comparar as mudanças ocorridas nos aspectos estudados ao longo do tempo. No trabalho longitudinal realizado com dois sujeitos disártricos (RV e LG), no período de um ano (agosto/2001 a agosto/2002), têm sido verificadas certas alterações prosódicas que podem indicar em que medida a fala deles foi irremediavelmente alterada em decorrência das lesões cerebrais e em que medida os sujeitos, ao se depararem com o estranhamento próprio e alheio em relação à própria fala, se utilizaram de elementos prosódicos já presentes no sistema da língua materna para tentarem torná-la mais compreensível para os ouvintes.

Uma das hipóteses é que o recurso a domínios prosódicos superiores (cf. SCARPA, 2000; no prelo) se deu em função de dificuldades de articulação ${ }^{1}$ decorrentes dos danos cerebrais apresentadas pelos sujeitos. Numa análise preliminar dos dados juntamente com relatos de entrevistas - pudemos constatar que, embora ambos os sujeitos recorram a elementos prosódicos para compensar as dificuldades articulatórias no nível segmental, eles fizeram opções diferentes nesse sentido. Enquanto a fala de RV (que apresenta um quadro disártrico mais grave) demonstra grandes variações melódicas, a de LG apresenta poucas variações. Além disso, conforme disse em entrevista, ele contraía propositalmente suas pregas vocais, e isso tornava sua voz mais grave. A justificativa 
dada por ele para tal atitude é que, ao fazer isso, ele "se lembrava" de que tinha que "mexer mais a boca" para falar, i.e., que ele tinha que articular melhor os sons. RV, por outro lado, produzia grandes variações melódicas sem se dar conta disso, i.e., inconscientemente.

Nesse sentido, um dos objetivos do trabalho é mostrar que o estranhamento que a fala desses sujeitos com disartria pós-traumática provoca nos ouvintes se deve não só à lentificação da velocidade de fala e às mudanças de qualidade de $\operatorname{voz}^{2}$ decorrentes das lesões cerebrais, mas, também, e principalmente, a essas estratégias prosódicas das quais eles se utilizam para viabilizar a inteligibilidade da própria linguagem oral. Em outras palavras, pretendo mostrar que os sujeitos cérebro-lesados em geral - e os disártricos em particular - se utilizam (ainda que intuitivamente, sem plena consciência disso) de determinados recursos prosódicos já disponíveis na língua para tentar tornar a própria fala mais compreensível - o que acaba promovendo uma reorganização prosódica na fala desses sujeitos.

Para apresentar essa reorganização prosódica, têm sido realizadas análises fonético-acústicas dos dados desses sujeitos no momento em que eles chegaram ao CCA (Centro de Convivência de Afásicos do Instituto de Estudos da Linguagem da UNICAMP) em 2001, para compará-las com os dados colhidos em 2002. Além disso, pretendo sistematizar, de acordo com os conceitos de prosódia presentes na literatura lingüística, as características da fala de RV (que, numa análise preliminar, apresentou uma subida de $\mathrm{F}_{0}$ nas sílabas tônicas) e na qualidade de voz mais baixa de LG (que apresentou pitch contour, curva de altura, mais baixa comparada ao sujeito-controle).

Na primeira parte, serão apresentadas algumas hipóteses referentes às estratégias lingüísticas utilizadas pelos sujeitos disártricos. $\mathrm{Na}$ segunda parte, serão apresentados alguns conceitos referentes a estudos sobre a relação entre prosódia e disartria. Na terceira, a metodologia; na quarta, serão apresentados os sujeitos e suas falas; na quinta, as estratégias lingüísticas, e na sexta parte, as conclusões preliminares. 


\section{HIPÓTESES}

As hipóteses aqui apresentadas se referem ao uso de elementos supra-segmentais, i.e., prosódicos, para compensar dificuldades articulatórias no nível segmental. Dos três elementos que compõem a prosódia, serão analisados dois: a duração ${ }^{3} \mathrm{e}$ a altura. ${ }^{4}$

Em relação à duração, a hipótese é que a lentificação da velocidade de fala é compensada pela redução silábica, i.e., os sujeitos procuram enfatizar a articulação das sílabas tônicas em detrimento das átonas na tentativa de falar mais rapidamente; e, no que se refere à altura, as variações visam contribuir para a inteligibilidade da fala, tanto através da redução, quanto através do aumento de $\mathrm{F}_{0}$.

\section{PROSÓDIA E DISARTRIA}

Segundo Felizatti (1998), a disartria corresponde a uma desordem na produção motora que afeta os padrões de movimento, precisão, coordenação e força dos órgãos fono-articulatórios. Além disso, envolve lesões motoras de origem geralmente traumática no sistema nervoso central, em níveis cerebelares e subcorticais, configurando comprometimentos fonético-fonológicos causados pelo enfraqueciento dos músculos fonatórios.

De modo geral, estudos relativos à prosódia e disartria concluíram que há lentificação generalizada da velocidade de fala, desarranjo rítmico causado pela neutralização da duração silábica, maximização do uso de pausas e não-redução das vogais átonas finais (cf. SCARPA, 2000). Desta forma, a alternância rítmica e o âmbito limitado da curva de altura (distância de $\mathrm{F}_{0}$ entre níveis altos e baixos dos contornos entonacionais) caracterizam alguns problemas de comunicação expressos pelos sujeitos disártricos que, contudo, exibem preservação de níveis da hierarquia prosódica, pois inserem pausas entre fronteiras prosódicas maiores (cf. SCARPA, 2000; no prelo). 


\section{METODOLOGIA}

A fala dos sujeitos disártricos LG e RV foi gravada em um gravador digital portátil - mini-disc da marca SONY (modelo MZ-R 700/R700 PC/ R700 DPC), em sessões fonoaudiológicas, no CCA (Centro de Convivência de Afásicos) do IEL-UNICAMP (Instituto de Estudos da Linguagem da Universidade Estadual de Campinas). As gravações foram feitas por mim durante três períodos de seis meses.

A primeira gravação ocorreu em 08/2001, quando foram gravados trechos de fala espontânea (relato de situação cômica) e leitura de um texto-controle; em 02/2002, gravamos uma entrevista na qual os sujeitos relatam as principais queixas em relação à própria fala e leitura do mesmo texto-controle; finalmente, em 08/2002, foi gravada uma conversa na qual os sujeitos falam sobre esportes e lêem, novamente, o mesmo texto.

Para análise acústica, as gravações foram segmentadas em orações e, em seguida, os espectrogramas foram analisados no programa PRAAT, desenvolvido por Paul Boersma, do Instituto de Ciências Fonéticas da Universidade de Amsterdam.

Um sujeito controle, i.e., sem lesão cerebral (TT) também realizou a leitura do texto com o propósito de fornecer um parâmetro comparativo no nível segmental. TT é paulista como LG e RV; nasceu em Jundiaí no dia 20/10/1978, é destro e musicista/músico, com escolaridade superior completa.

O texto lido foi "História Estranha", de Luiz Fernando Veríssimo. A escolha desse texto foi baseada na curta extensão (21 orações) e no fato de todas as orações serem declarativas, o que permite a manutenção de um padrão entonacional. De acordo com Moraes 2000: 183,

em português, como na maioria das línguas conhecidas, o padrão da declarativa é caracterizado por uma queda de $\mathrm{F}_{0}$ no fim da pronúncia (mais precisamente, na tônica final), enquanto o pitch inicial está no nível médio. 


\section{OS SUJEITOS DISÁRTRICOS}

\subsection{LG}

LG nasceu em 23/05/1970 em São Paulo/SP. Em outubro de 1998, aos 28 anos, sofreu um acidente automobilístico. Em exames imediatamente pós-acidente, foram observadas lesões corticais e subcorticais caracterizadas por áreas hiperdensas (edemas) em região frontal esquerda, cápsula nuclear direita e região parietal alta direita.

Ficou internado durante 40 dias e em coma induzido por 10 dias. Teve traumatismo craniano à direita e, como seqüelas, uma lesão cerebelar relacionada aos aspectos motores da face e da fala, contusão cerebral e lesão axional difusa grave. Três meses após o acidente, apresentou euforia e fala inarticulada. Além disso, teve anacusia (perda da audição) à direita. O eletroencefalograma e o mapeamento cerebral permanecem normais. Houve um aumento das partes moles na região parietal direita e há presença de áreas hiperdensas na região frontal esquerda, cápsula nuclear direita e região parietal alta direita, com hipodensidade adjacente.

LG é destro e, atualmente, aos 32 anos, trabalha como engenheiro civil.

\subsubsection{A Fala de LG}

As características gerais da fala de LG são:

- achatamento de $\mathrm{F}_{0}$; ex: (ver figuras 1 e 2 no final do texto);

- qualidade de voz: breathy voice;

- impressão auditiva geral: monotônico. ${ }^{5}$

\section{2. $\mathrm{RV}$}

Nascido em 16/03/1973, em Campinas/SP, RV sofreu um acidente automobilístico em 12/07/1998 aos 25 anos de idade. Ficou em coma induzido durante 15 dias e teve traumatismo craniano à direita e lesão axional difusa grave, lesões corticais no lobo temporal 
esquerdo com redução cortical, na pirâmide direita, ponte e pedúnculo cerebral direito, além do corpo caloso. Fez traqueostomia por 1 ano e, em decorrência de estenose, teve uma retirada cirúrgica de anéis traqueais com subseqüente inserção de prótese de silicone. Voltou a falar três meses após o acidente. Em fevereiro de 1999, iniciou terapia fonoaudiológica e ecoterapia. Apresenta ausência de sensibilidade na porção anterior média e posterior do lado direito da boca e face.

RV é canhoto e, atualmente, aos 29 anos, estuda Direito.

\subsubsection{A Fala de RV}

A fala de RV apresenta as seguintes características:

- prolongamento e maximização do uso de pausas; tom alto nas sílabas tônicas; mudança de tessitura para faixa alta; ex: (ver figuras 1 e 3 no final do texto)

- qualidade de voz: creaky voice ${ }^{6}+$ falsetto $^{7}$;

- impressão auditiva geral: hipermelódico. ${ }^{8}$

\section{ESTRATÉGIAS LINGÜÍSTICAS}

Tanto LG quanto RV desenvolveram estratégias lingüísticas para lidar com a própria fala após o acidente. Por exemplo, ao ser questionado a respeito do tom vocal baixo, LG disse que força intencionalmente as pregas vocais para se obrigar a articular melhor os sons. Desta forma, ele cria uma dificuldade articulatória (tensão voluntária e excessiva das pregas vocais) para tentar compensar outra, que envolve a produção de elementos segmentais (sílabas, palavras, frases).

A brevidade silábica característica da fala de LG também pode ser justificada como uma estratégia que visa compensar a lentificação da velocidade de fala, i.e., como uma tentativa de normalizar a duração.

Já RV, ao ser informado que falava com grandes variações melódicas e entonacionais, particularmente nas sílabas tônicas, 
explicou que isso foi um recurso inconsciente do qual ele se utiliza para manter a atenção dos interlocutores - que, de uma maneira geral, tendiam a se aborrecer com a fala lenta dele. Assim, para compensar dificuldades de articulação no nível segmental, RV se vale de recursos suprassegmentais presentes na língua, intensificando-os.

Além disso, segundo ele o tom da voz dele ficou muito baixo/ grave após o acidente, e as variações melódicas e entonacionais pareciam contribuir para atenuar essa impressão.

\section{CONCLUSÕES PRELIMINARES}

Devido às dificuldades de articulação decorrentes das lesões cerebrais, tanto LG quanto RV se utilizaram, conscientemente ou não, dos elementos prosódicos já presentes e disponíveis na língua para tentar melhorar a inteligibilidade da própria fala. Tal fato pode ser constatado a partir da análise fonético-acústica da fala dos sujeitos, que mostra alterações prosódicas em relação a um padrão.

\section{NOTAS}

${ }^{1}$ Tais dificuldades envolvem enrijecimento e fadiga muscular, o que perturba a articulação apropriada de fonemas, especialmente de consoantes (tepe e grupos consonantais) e a velocidade de fala. A maximização do uso de pausas e a lentificação da velocidade de fala ocorrem devido às dificuldades de controle respiratório dos sujeitos, que têm que inspirar mais vezes para administrar o fluxo de ar destinado à fala e à respiração propriamente dita.

2 "Aspecto auditivo geral de uma determinada voz, com a contribuição de fatores laringais e supralaringais". (LAVER, 1980). A qualidade de voz deriva de duas fontes diferentes: das características anatômicas do aparato vocal do falante e do uso que o falante faz do aparato vocal. "A noção de qualidade de voz é básica para o estabelecimento de qualquer tipo de estrutura conceitual que apresente a gama completa de contrastes lingüísticos e prosódicos. (...) Ela corresponde a uma combinação de parâmetros acústicos e articulatórios que variam de forma independente, sendo que os atributos mais importantes são altura, volume, duração e timbre". (CRYSTAL, 1969: 123) 
${ }^{3}$ A duração é "a quantidade de tempo consumida por um evento discursivo; geralmente é expressa em milésimos de segundo (msg). É um traço fonético.” (cf. LAVER, 1994: 431). Pode ser vista como a duração de tempo que um falante decide continuar a produzir uma unidade lingüística, a duração dos correlatos acústicos da unidade no espectrograma ou como a duração de tempo na qual o ouvinte ouve a unidade. (cf. CRUTTENDEN, 1986/1992).

${ }^{4}$ A altura é a variável do pico de voz em uma sílaba ou em um número de sílabas sucessivas. Fisiologicamente, depende da taxa de vibração das pregas vocais dentro da laringe. A taxa de vibração das pregas vocais (correlato articulatório) é refletida na medição acústica da Freqüência Fundamental $\left(\mathrm{F}_{0}\right)$. Em outras palavras, $\mathrm{F}_{0}$ é o correlato acústico (físico) da altura. (cf. CRUTTENDEN, 1986/1992).

5 Tom de voz que apresenta âmbitos limitados da curva de altura, i.e., baixas variações de $\mathrm{F}_{0}$.

${ }^{6}$ A voz do tipo creaké caracterizada pelo fornecimento de input com pulsos de energia para o trato vocal. Esses pulsos, porém, ocorrem numa freqüência muito baixa e são espaçados irregularmente no tempo (cf. LAVER, 1994: 194-195), o que gera vibração irregular das pregas vocais.

${ }^{7}$ No falsetto, as pregas vocais são esticadas longitudinalmente de frente para trás, tornando-se relativamente finas na secção cruzada, com as margens glotais das pregas ficando particularmente finas. A glote fica ligeiramente aberta. Assim, o falsetto é acompanhado por um leve sussuro, já que o fluxo de ar pulmonar consegue escapar continuamente pela passagem glotal. Além disso, a pressão subglotal é caracteristicamente mais baixa do que na fonação vozeada comum, em parte por causa do contínuo vozeamento transglotal (LAVER, 1994: 197).

${ }^{8}$ Que apresenta variação excessivamente alta da altura (cf. COLSHER, COOPER \& GRAFF-RADFORD (1987:379)).

\section{REFERÊNCIAS BIBLIOGRÁFICAS}

COLSHER, P. L.; COOPER, W.E.; GRAFF-RADFORD, N. Intonational variability in the speech of right-hemisphere damaged patients. Brain and Language 32, p. 379-383, 1987.

CRUTTENDEN, A. Intonation. Cambridge: Cambridge University Press, 1986/1992.

CRYSTAL, D. Prosodic systems and intonation in English. Cambridge: Cambridge University Press, 1969.

FELLIZATTI, P. Aspectos fonético-fonológicos da disartria pós-traumática: um estudo de caso. 1998. Dissertação (Mestrado) - IEL/UNICAMP. 
LAVER, J. Principles of phonetics. Cambridge: Cambridge University Press, 1994. LAVER, J. The phonetic description of voice quality. Cambridge: Cambridge University Press, 1980.

MORAES, J. A. Intonation in Brazilian Portuguese. In: HIRST, D.; DI CRISTO, A. (Ed.). Intonation systems: a survey of twenty languages. Cambridge: Cambridge University Press, 2000. p.179-194.

SCARPA, E. M. Abordagens prosódicas à linguagem de sujeitos cérebro-lesados. GEL/2000.

SCARPA, E. M. Dificuldades prosódicas em sujeitos cérebro-lesados. Revista ALFA (no prelo).

VERISSIMO, L. F. História Estranha. In: Comédias para se ler na escola. São Paulo: Ed. Objetiva, 2000. p.47. 


\section{FIGURAS 1, 2 E 3}

\section{A) Figuras 1 e 2}

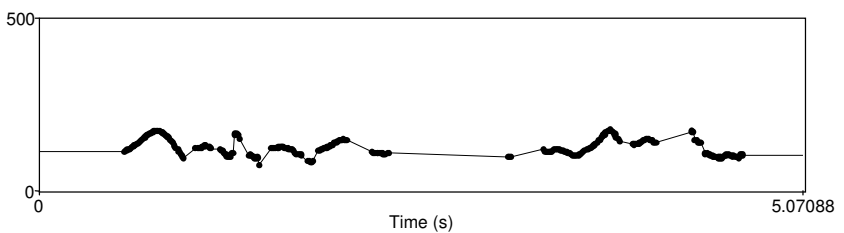

Figura 1 - TT: "O homem tenta dizer alguma coisa, mas não encontra o que dizer."

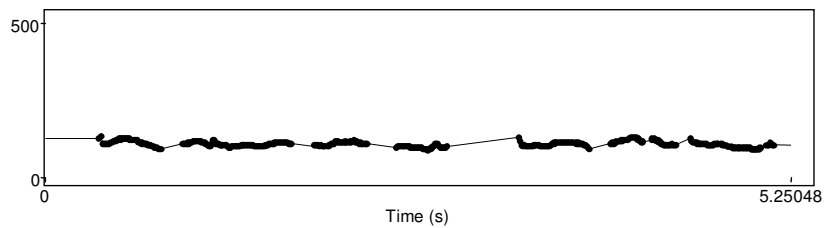

Figura 2 - LG: "O homem tenta dizer alguma coisa, mas não encontra o que dizer."

Leitura da frase "O homem tenta dizer alguma coisa, mas não encontra o que dizer", feita pelo sujeito controle TT e pelo paciente disártrico LG. O F de $_{0}$ LG é achatado em relação ao do controle. Além disso, a pausa entre a primeira e segunda orações é reduzida.

\section{B) Figuras 1 e 3}

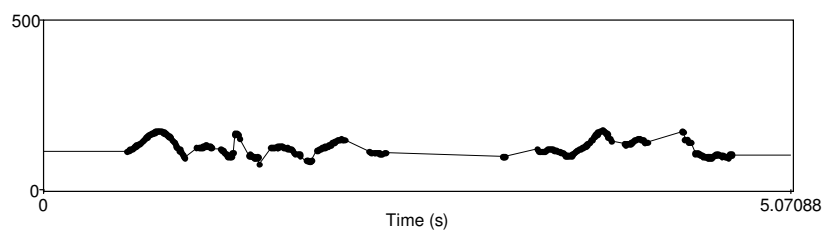

Figura 1 - TT: "O homem tenta dizer alguma coisa, mas não encontra o que dizer."

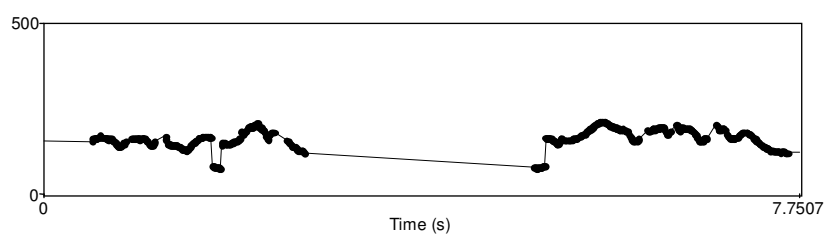

Figura 3 - RV: "O homem tenta dizer algưmanas não encontra o que dizer."

Leitura da frase "O homem tenta dizer alguma coisa, mas não encontra o que dizer", feita pelo sujeito controle TT e pelo paciente disártrico RV. O $\mathrm{F}_{0}$ de RV é hipermelódico em relação ao do controle. Além disso, a pausa é prolongada. 